\title{
CREATIVIDAD PUBLICITARIA Y RETÓRICA De la metáfora a los efectos especiales
}

\author{
Isidoro Arroyo Almaraz \\ Profesor de Creatividad Publicitaria. Universidad Rey Juan Carlos.
}

\section{Resumen}

La Creatividad Publicitaria y la Retórica comparten elementos comunes. En este artículo, veremos cómo estas dos materias, con muchos siglos de existencia, abren nuevas vías de investigación. Las ideas se representan verbal y visualmente a través de los distintos lenguajes. Su agrupación en palabras y oraciones, imágenes y planos, efectos especiales conforman mensajes publicitarios cuyo objetivo principal es persuadir al consumidor para ser leídas, oídas, vistas y recordadas en imágenes mentales.

\section{Palabras clave}

Retórica - Creatividad - Publicidad - Imágenes mentales - Efectos Especiales

\begin{abstract}
Advertising Creativity and Rhetoric are two disciplines with common factors. In this article we will see how these two matters, with many centuries of existence, open new routes of investigation. The idea representation are performance in verbal and visual languages. Their grouping in words and phrases, pictures and planes, special effects, conforms advertisings whose primary target is to persuade the reader to be read, heard, watched and to recall in imagery.
\end{abstract}




\section{Key words}

Rhetoric - Creativity - Adversiting - Imagery - Special Effects.

O poeta é um fingidor

Finge tâo completamente

que chega a fingir que é dor

a dor que deveras sente.

(Fernando Pessoa)

\section{Creatividad Publicitaria y Retórica}

La retórica ha aportado tradicionalmente a la publicidad un método de creación, porque como bien decía Jacques Durand (1972, 110). “La retórica es el repertorio de las diferentes maneras con las que se puede ser original”. Por tanto no es sólo un mero ornamento para decorar los mensajes de la publicidad, sino que como señalara González Martín (1996, 274): “es un recurso para la elaboración de los sentidos(...) los anuncios se producen más de acuerdo con la retórica, que con la referencia al mundo, a los hechos”.

El campo de aplicación tradicional e histórico del estudio de la retórica, tal y como se puede apreciar en el magnífico estudio del profesor Francisco García, publicado en este mismo número, se ha utilizado mayoritariamente en la retórica del lenguaje.

El lenguaje nos ha permitido acercarnos a lo inefable. Este conocimiento trascendente nos ha llegado de la mano de la lengua natural, que Jakobson contraponía a la lengua científica. La lengua natural, gracias a la retórica, ha sido y es la fuente de imaginación y de la creación. Por ello, la retórica se ha definido como el arte de la palabra fingida, que usada originariamente en la poesía, convertía al poeta en um fingidor.

Este arte ancestral de la poética nos ha permitido alcanzar cimas inefables para el conocimiento. Carlos Bousoño (1976, 101 y ss) nos lo explica: "La poesía debe darnos la impresión de que, a través de meras palabras, se nos comunica un conocimiento de muy especial índole: el conocimiento de un contenido psíquico(...) que en la vida real se ofrece como algo individual (...) Aunque la persona 
concreta del poeta no se compromete en términos de realidad con lo que literalmente dice su poema, el hombre genérico que en el poeta hay se compromete con la vida. Quien habla en el poema no es el poeta, pero sí es la imagen de un ser humano, que naturalmente existe en un mundo imaginariamente humano también"

El universo poético se vio acompañado por la invasión masiva de imágenes y sonidos, que llenaron nuestro imaginario a lo largo del siglo XX. El estudio de la retórica, se amplió al estudio de la retórica de la imagen, cuyos orígenes los encontramos, entre otros autores, en Roland Barthes cuando en la década de los 70 se planteaba la necesidad de una retórica general común al sueño, a la literatura y a la propia imagen: "la retórica de la imagen sólo podría constituirse a partir de un inventario bastante amplio(...) de las figuras señaladas antes por los Antiguos y los Clásicos”. (nº 4, 50, Communication).

La imagen se ha convertido en el referente universal a partir del cual construimos el mundo en imágenes. Hemos pasado de representar el mundo en imágenes a interpretar todo lo que nos rodea como una imagen. Este giro icónico desplaza la eficacia de la creatividad publicitaria, desde la imagen externa hacia la imagen interna. Por ello adquiere una gran importancia las representaciones internas no verbales, de carácter espacial, que los sujetos realizan de las imágenes publicitarias.

Las imágenes publicitarias y los efectos especiales se están demostrado muy eficaces en el proceso de generación de imágenes mentales en los consumidores, porque sirven para comunicar, tanto atributos de los productos como conceptos abstractos, a la vez que facilitan el acceso a nuevas metáforas de la realidad.

Por todo ello, consideramos que, la investigación sobre creatividad publicitaria y retórica, nos desvelará un universo de ventajas, que ayudarán a aportar soluciones a los problemas de comunicación, que los anunciantes reclaman de las agencias de publicidad.

Los conceptos retóricos, y sus tipologías nos facilitan el acceso automático a un mundo lleno de recursos. Como apunta Moliné (1988,24): “La retórica no es la creación sino un análisis de cómo es la creación y cómo producir la creación de una obra persuasiva”.

La publicidad, por tanto, está llena de retórica, “es un discurso fingido, basado en la utilización de un doble plano del lenguaje: el normativo, que existe realmente, pero que tiene poco significado, y el 
figurado, que tiene sentido, pero no existe; produciéndose de este modo una sobresignificación que el uso estándar del lenguaje no tiene. Los mecanismos retóricos son funciones que tratan de poner en contacto ambos planos”. González Martín (1996,274)

La retórica se ha revelado como un dispositivo de eficacia comunicativa, a la vez que se ha convertido en la vía privilegiada, primero con el lenguaje, y después con la imagen, para producir los efectos necesarios que desautomatizan los discursos y los hacen imprevisibles, bellos y llenos de sentido.

Para ello utiliza un discurso fingido que, como señalaba González Martín, se construye en los ámbitos del significado y del sentido y en el ámbito de la trasgresión de la norma.

La elaboración del significado, se produce en el momento de la creación del mensaje, cuando el creativo publicitario, que conoce la proposición real, la convierte en una proposición figurada.

La elaboración del sentido, se produce en el momento de la recepción del mensaje donde el consumidor, que conoce la proposición figurada, alcanza su plenitud cuando transforma en real la proposición figurada.

La operación retórica, consiste en dar sentido al significado del mensaje, mediante una transformación del segundo en el primero, por la que se restituye la proposición original y se le da el significado simple que tuvo en su origen.

Además, toda figura retórica, participa de las operaciones de transformación de una proposición en otra, participa también de la operación de trasgresión de la norma.

El juego de la trasgresión del lenguaje se materializa con la trasgresión del lenguaje normativo. El lenguaje retorizado participa de abusos gramaticales y/o ortográficos, devalúa la realidad con el empleo del humor, proyecta nuestros deseos con el juego del erotismo, etc.

El juego de la trasgresión de la imagen se materializa con la trasgresión de la imagen del mundo real. La imagen retorizada juega con la imaginación, la ilusión, la alucinación, y sobre todo con la metáfora visual creativa, de la que nos ocuparemos a continuación. 


\section{La Metáfora Creativa}

La metáfora se ha utilizado y se utiliza en publicidad gracias a la enorme capacidad que tiene para representar conceptos, a la vez que facilita el aprendizaje sobre la marca, el producto o el servicio.

La metáfora, se fundamenta en una relación por analogía, que va desde lo abstracto a lo concreto. Comparte con la analogía la operación mental de semejanza entre dos elementos y se diferencia del símbolo en que éste va de lo concreto, lo representado, a lo abstracto; mientras que la metáfora, como ya hemos dicho, va de lo abstracto a lo concreto.
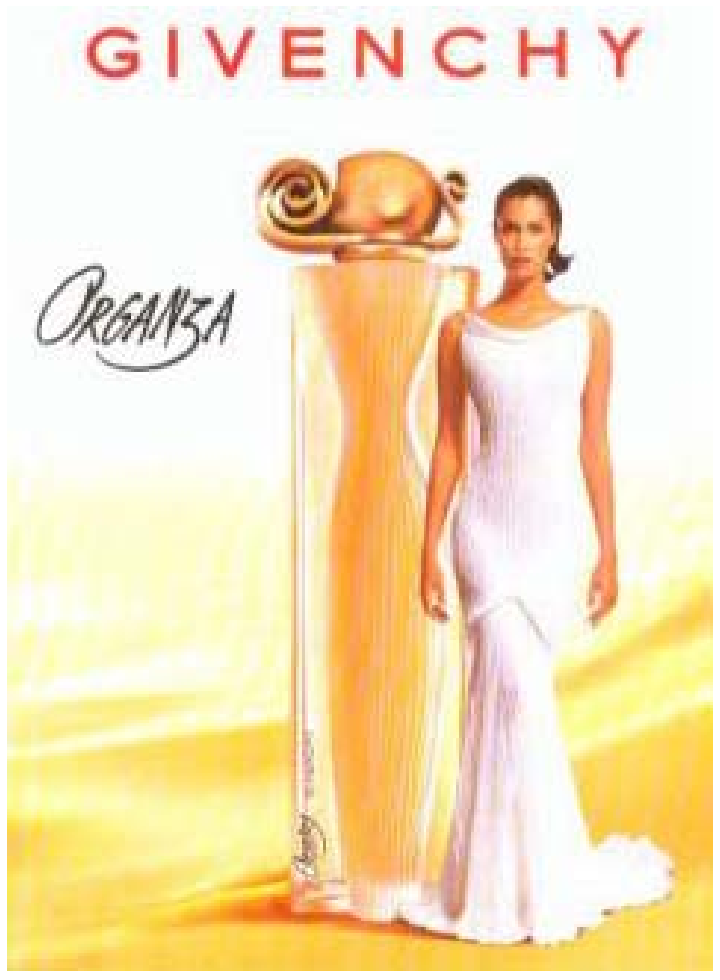

En esta imagen podemos establecer una relación metafórica, por analogía visual, entre las formas de la sombra del perfume en el envase y las formas de la mujer.

Veamos otro ejemplo de relación metafórica, por analogía semántica, que nos proporciona Isidro Moreno (2003, 206). Este autor nos recuerda, con muy buen criterio, como se le atribuye al hijo de Vargas Llosa la creación del lema electoral “Vota limpio, vota en blanco”, propuesto en las últimas elecciones peruanas. Este eslogan metafóricamente relaciona el plano real —la papeleta en blanco—, con el plano evocado — la limpieza electoral—. Ello tiene una conexión con la historia reciente del Perú de Fujimori y los escándalos de corrupción electoral que se produjeron. Simbólicamente, 
relaciona el color blanco de la papeleta con la limpieza. El adjetivo limpio, nos traslada, por su valor polisémico, al valor ético que se contrapone a corrupción y se asocia por analogía, con el color blanco, símbolo de la pureza.

Como acabamos de ver, las imágenes publicitarias tienen una gran capacidad para representar conceptos, abstracciones, acciones o metáforas que se convierten en expresiones de ideas a veces muy complejas. Las analogías y las metáforas entre la información nueva e informaciones que ya se poseen facilitan, como ya hemos dicho, el aprendizaje sobre la marca, el producto o el servicio.

\section{1. ¿Cómo trabajan las imágenes publicitarias?}

Los diseños de los anuncios anticipan un lector que conoce ciertas convenciones pictóricas y que comparten experiencias visuales con los autores. Leer las imágenes es una habilidad adquirida.

Aplicando las aportaciones de Rouquette (1977) sobre la metáfora al estudio de las imágenes publicitarias de Linda M. Scott (1994), podemos concluir que existen, por lo menos, tres modelos distintos de anuncios publicitarios que se ajustan a los tres supuestos de recubrimientos que determinan la riqueza de la analogía propuestos por Rouquette (1979). Este autor delimita la metáfora como un mecanismo de correspondencias y recubrimientos analógicos entre dos objetos o conceptos. Cada uno de estos objetos o conceptos está definido por un conjunto de propiedades que, utilizando la terminología de la teoría de conjuntos, podemos clasificar como:

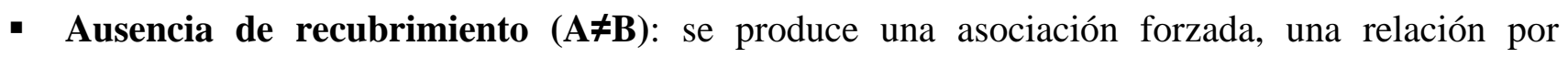
combinación aleatoria, donde un objeto no tiene ningún elemento en común con otro. Cuando el metaforado y el metaforante son conjuntos aislados, nos encontramos con anuncios con imágenes irrelevantes, que funcionan a través de despertar emociones, no suelen tener ni body copy ni nada que se parezca a un titular, excepto la marca. 


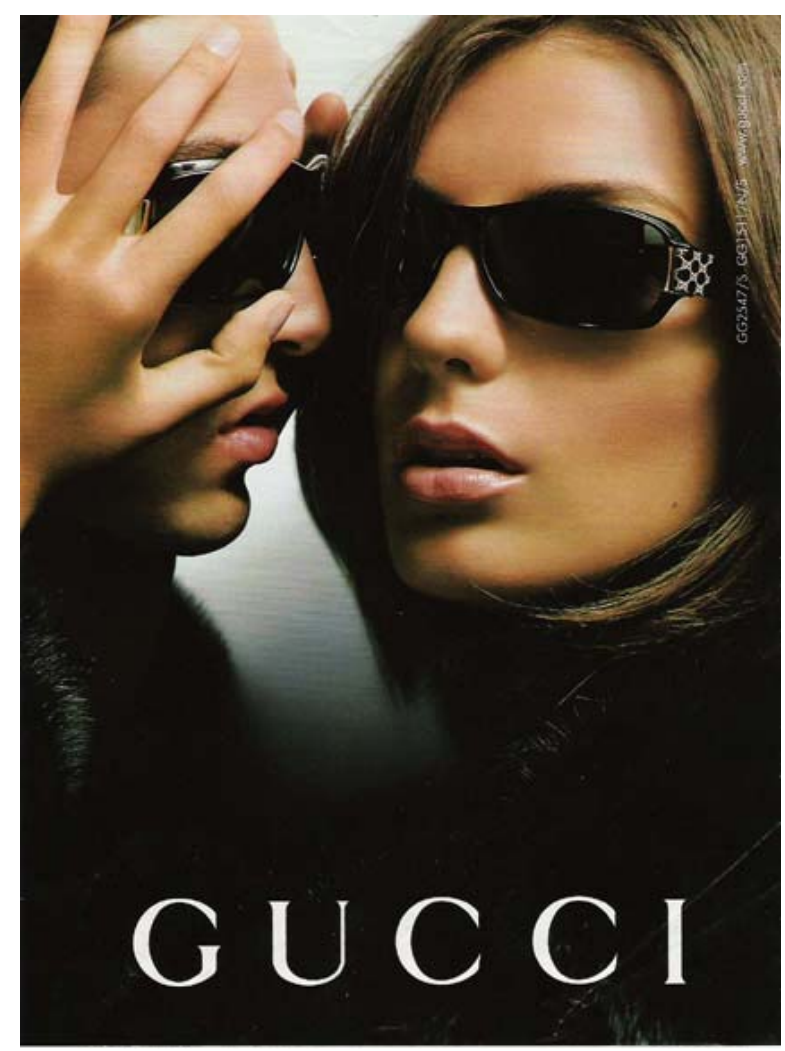

Sólo la emoción de la proximidad y del encuentro nos hace preguntarnos por el beneficio de la marca. ¿Un perfume? ¿una marca de gafas?,... Lo único importante, una marca connotada de emociones.

El mensaje está en la imagen, pero la promesa del anunciante es indescifrable por ausencia de imágenes que ilustren los atributos del producto. El argumento está presentado figurativamente, es un tropo. El anunciante presenta su proposición de manera fresca para que el público piense sobre ese tema cercano desde una perspectiva imprevista. El uso de este tipo de metáforas es eficaz porque rompe el escepticismo y el cansancio de los consumidores saturados de la publicidad repetitiva.

- Interjección de conjuntos (AกB) o asociación de elementos: se produce una transferencia de algunos términos de un objeto o concepto hacia el otro. De ahí se obtiene un subconjunto de elementos comunes del objeto y de su representación icónica. De todos modos es posible definir zonas de recubrimiento comunes a los dos conjuntos.

Dentro de este modelo nos encontramos con anuncios apoyados en fotografías, que aún siendo figurativas, no copian el producto de manera realista. Suelen ser fotografías muy cercanas (primeros planos o planos detalle), en los que la imagen ocupa toda la página. Se produce una 
manipulación sensitiva de símbolos aprendidos de acuerdo con estrategias normativas de procesamiento. La imagen y la composición son variables independientes

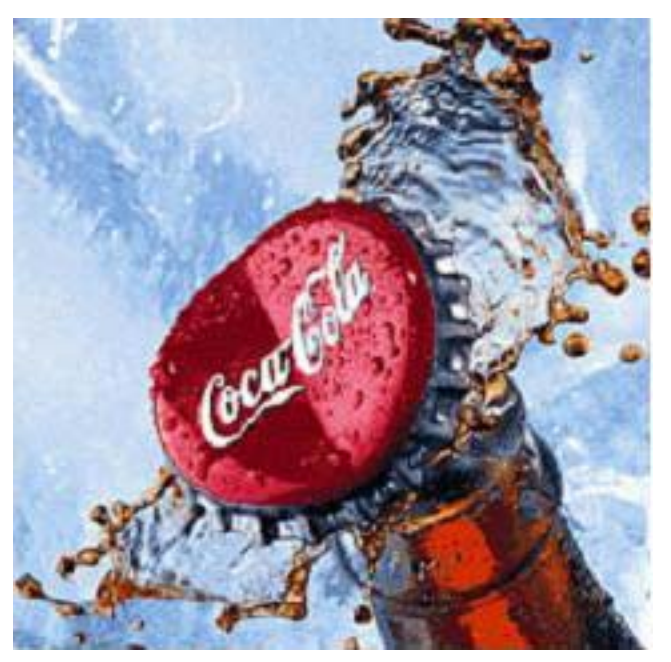

Un momento, la apertura de la botella, define una sensación, la frescura.

- Identidad o asociación total (AUB): puede ser una analogía muy cercana con un recubrimiento casi total. Nos encontramos con los anuncios que enseñan el producto y sus características clave de forma objetiva sin ninguna distorsión, porque no necesitan ser interpretadas. Las fotografías son relevante porque ilustran atributos tangibles que refuerzan la promesa del anunciante. Copian fotográficamente el producto y son absorbidos en la mente del consumidor sin necesidad de compromiso o estrategia cognitiva.

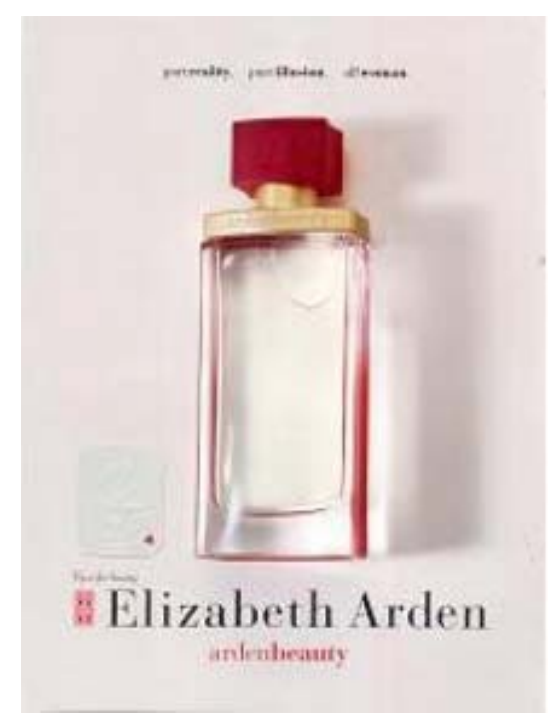

Lo que veo, veo y no lo puedo refutar. 


\section{2. ¿Cómo trabajan las metáforas?}

La metáfora sustituye los objetos de deseo que muestra la publicidad por imágenes mentales en el pensamiento abstracto y el inconsciente. El enunciador y el enunciatario convergen con el enunciado. El que habla y el que escucha se sitúan en la posición del que desea. El que habla, que se muestra como una gestalt, controla nuestra mirada mostrándose en planos detalle, ofreciéndose en planos subjetivos y, el que escucha, desea resolver sus necesidades, construyendo un deseo con la imagen del que habla.

En el plano de la imagen mental, la imagen del objeto se metamorfosea en la imagen de deseo, pero en el plano de la imagen real las personas miran al anuncio y éste no puede mirarles. Tomando como préstamo los dos últimos versos de la primera estrofa del "Romance Sonámbulo" (1982, 97) de Federico García Lorca, diríamos que: ” (...) las cosas la están mirando/ y ella no puede mirarlas”.

González Requena (1999, 58-61) habla de metáfora delirante, porque el consumidor se siente mirado y reconocido por una imagen que no mira, que es imaginaria. Para este autor, refiriéndose a los spots de perfumes que presentan imágenes de mujeres junto con imágenes de frascos de perfumes (como las que hemos presentado anteriormente), la imagen de la mujer se convierte en un perfume y se carga de dulzura, sensualidad y aroma, y el frasco de perfume adquiere la promesa que sólo la mujer encierra. Sin embargo, para este autor, ni la mujer ni el perfume, actúan como significantes de la metáfora, sino como imágenes identificatorias, gestálticas, que buscan la imagen de plenitud que se asocia al Yo ideal (en términos de psicoanálisis).

Se habla, más que de metáfora, de metamorfosis en la que la mujer que mira, se convierte en frasco de perfume a través de la operación de fusión entre imagen y envase del espectador. El espectador se deja invadir por la imagen total y eleva la metáfora sustitutoria a metamorfosis identificatoria.

Lógicamente, el beneficio para el producto está en que la metamorfosis no admite la reversibilidad de la operación, ni tan siquiera el análisis de la operación desde el propio pensamiento. 


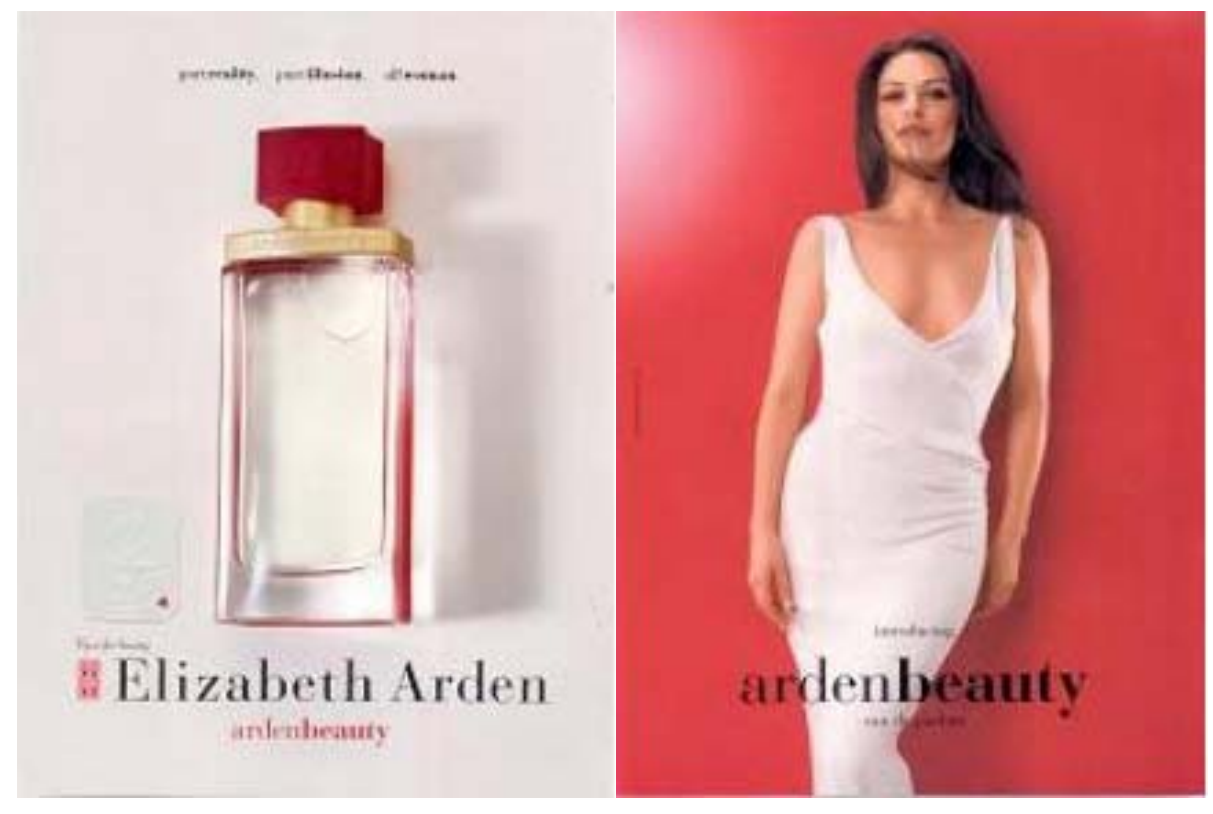

Las cosas son como parecen y no como son.

Aunque en el plano del discurso se producen dos tropos:

La metonimia, que transforma el envase en perfume y, la metáfora, que transforma la mujer en envase, en el plano del deseo el envase se transforma en falo y se convierte en ese oscuro objeto de deseo que, trascendiendo a su condición de fetiche y de símbolo, se convierte en la mismísima imagen absoluta del Yo ideal. Esto evidentemente nos hace regresar al estadio primario del narcisismo.

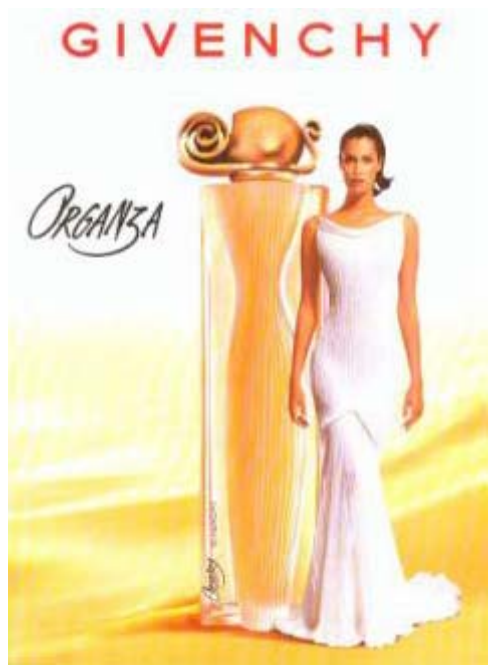


Más allá de la metáfora y la metonimia hay dos significantes sin sustitución entre ellos, pero con fusión que se convierten, ante los ojos del espectador, en la sensación de plenitud. En la metáfora delirante, se sustituye la metáfora por metamorfosis y la sustitución por fusión.

\section{La Tecnocreatividad: Uso o abuso de efectos especiales.}

Las nuevas herramientas tecnológicas abren nuevas posibilidades de comunicación, que alcanzan sus cotas más altas cuando se trata de dar a conocer productos tecnológicos a públicos jóvenes. Entonces la eficacia persuasiva se consigue a través de los entornos tecnológicos, que se convierten en la nueva metáfora de progreso, ya que facilita la generación de sentimientos favorables hacia los nuevos productos o servicios. El público más joven, saturado de mensajes publicitarios, rechaza la publicidad tradicional y sólo asimila las propuestas que proceden de las nuevas tecnologías.

Nuestra hipótesis sugiere que el incremento considerable de tecnologías de la comunicación y de la información, en el proceso de elaboración y de recepción de los mensajes publicitarios, automatiza el consumo publicitario. Y los consumidores atienden cada vez más a los mensajes con impacto emocional y a aquellos otros que nos sorprenden por los efectos especiales.

Los resultados de este modelo de creatividad, se materializan en la gran oferta publicitaria de buenos diseños de realización, en detrimento de una publicidad con mayor creatividad.

Por lo que nos preguntamos ¿qué puede aportar la tecnología a la creatividad? En nuestra opinión:

Facilita la atención a los mensajes y acelera el proceso de toma de decisiones. Aunque cada consumidor marca su propio ritmo de consumo, sin embargo, se ha acelerado el proceso de toma de decisiones y de atención a los mensajes, motivado por una creciente exigencia de eficacia y de inmediatez en las respuestas.

No hay tiempo para elegir y quien construye mensajes que destaquen captura, antes que nadie, las miradas flotantes que encuentran lo que no buscan en el cosmos de la información. 
Este nuevo concepto del tiempo, contribuye al éxito de los anuncios que se construyen atendiendo a los valores de "la razón técnica", que no es otro que el de la productividad en la fabricación de textos llenos de recursos expresivos; mensajes, por otra parte, colmados de efectos especiales para hacer posible que existan conceptos que antes no existían, mundos imposibles que podemos visualizar a través de imágenes.

La metáfora del mundo de Matrix, que nos hace sospechar que vivimos en un mundo no real, la construimos a través de mejorar nuestro saber y hacer técnico, porque éste nos facilita una interrelación mayor con mundos ficticios que nos apartan de otras realidades menos tecnológicas.

Construimos, cada vez más, nuestros deseos a través de estas nuevas experiencias de interacción con mundos ficticios y al final aceptamos automáticamente las propuestas de comunicación y de consumo coherentes con esta nueva concepción de la vida. Basta recorrer las calles de nuestras grandes ciudades, para comprobar cómo, las propuestas difundidas a través de medios tecnológicos, llegan con prontitud y se instalan en el imaginario colectivo, antes de que dé tiempo a reflexionar sobre sus consecuencias.

anuncio 12 playstation-riquezamental.wmv

La imagen deformada de la modelo (¿real o imaginaria?) de este anuncio se convirtió en objeto de culto para un sector de la juventud asiática, hasta el punto de que algunos jóvenes desearon deformarse la cara para parecerse a la modelo.

\subsection{De la personalidad de la marca a la personificación del producto}

La tecnología de la metáfora, que tan buenos resultados ha producido para la imagen de marca, está compartiendo su estrellato con la tecnología de la personificación apoyada en el uso de los efectos especiales que permiten visualizar los atributos del producto sin necesidad de que los tengamos que imaginar.. Por lo que consideramos que la creatividad publicitaria centrada en la metáfora, está compitiendo por la notoriedad con los nuevos efectos especiales, que se imponen por doquier, a 
través de la personificación de vacas que bailan en un anuncio de leche, gatos incendiados que siembran el pánico en un anuncio de coches, o que juegan al fútbol, perturbadoras lámparas, etc.

\section{Personificación.wmv}

Personificación lámpara nintendo-sobrenatural.wmv

Anuncio 24 citroenrobot.wmv

Las propuestas creativas que nos ofrecen a los consumidores, a través de los anuncios publicitarios, se apoyan cada vez más en “saberes técnicos”compartidos que van dirigidos a conseguir una respuesta inmediata de sorpresa, notoriedad y aceptación de la propuesta.

Las presencia constante y cambiante de nuevos lenguajes y entornos tecnológicos, basados en los efectos especiales en la publicidad, facilitan la adhesión del gran público que, deseoso de integrarse en el mundo de progreso que nos hace cercano lo lejano y presente lo futuro, modifica sus viejas percepciones de la realidad social para adaptarse al nuevo conocimiento compartido.

\section{Conclusiones}

1. La metáfora se ha utilizado y se utiliza en publicidad gracias a la enorme capacidad que tiene para representar conceptos, a la vez que facilita el aprendizaje sobre la marca, el producto o el servicio.

2. La creatividad publicitaria que se apoya en los efectos especiales busca la eficacia persuasiva. Por lo que:

a. Mejora la belleza de los entornos con los que envuelve sus mensajes y presenta sus productos y servicios.

b. Crea conceptos nuevos donde prevalezca el valor de la libertad de acción.

c. Permite experimentar sensaciones nuevas con las que los consumidores aprendan a implicarse con los mensajes.

d. Incrementar el valor de la notoriedad de los productos y marcas.

e. Automatiza los procesos cognitivos que intervienen en la atención del público. 
f. Reduce el desgaste por cansancio.

g. Incrementa de información como consecuencia del aumento de la velocidad.

h. Fomenta el consumo compulsivo de algunos productos para favorecer la entrada en el mercado de nuevos productos o actualizar los viejos productos o servicios.

\section{Bibliografía}

ARROYO ALMARAZ, I. (2004), La Creatividad y la razón tecnológica en la argumentación publicitaria. En Creatividad y Sociedad nº 6. págs. 27-34.

ARROYO ALMARAZ, I. GARCÍA GARCÍA, F Y MARTÍNEZ VAL, J., (2001) Imágenes y Cultura. Del cerebro a la tecnología. Laberinto Comunicación Madrid.

BAÑOS, M. (2001), Creatividad y publicidad. Laberinto Comunicación. Madrid.

BARTHES ROLAND ( $\mathrm{n}^{\circ} 4,50$, Communication).

BOUSOÑO C. (1976), Teoría de la expresión poética. Gredos. Madrid.

DURAND, J. (1972), Retórica e imagen publicitaria. En Análisis de las imágenes. Christian Metz y otros. Editorial Tiempo contemporáneo. Págs 81-112.

GARCÍA GARCÍA, F. (1991), Estrategias creativas. Vicens-Vives. Madrid.

GONZÁLEZ MARTÍN, J.A. (1996), Teoría general de la publicidad. Fondo de Cultura Económica. Madrid.

GONZÁleZ REQUENA, J. Y ORTIZ DE ZÁRATE, A. (1999), El Espot Publicitario. Las metamorfosis del deseo. Cátedra, Signo e Imagen. Madrid.

MORENO, I. (2003), Narrativa Audiovisual Publicitaria. Piados. Barcelona. 
ROUQUETTE, M.L. (1977), La creatividad. Huemul. Buenos Aires.

SCOTT, L.M. (1994), Images in Advertising: The Need for a Theory of Visual Rhetoric. Journal of Consumer Research. Vol 21, 252-273.

www.publitv.com Los spots publicitarios han sido tomados de esta página con finalidad didáctica, para ilustrar los conceptos que en el artículo se explican. Agradecemos a los gestores de dicha página el acceso gratuito a dicha información. 